

\title{
Price Variability and Marketing Method in the Non-Ferrous Metals Industry
}

\author{
Isabel Figuerola-Ferretti* ${ }^{*}$ Christopher L. Gilbert ${ }^{\dagger}$ \\ September 1999 \\ revised October 2000
}

\begin{abstract}
We examine the impact of the pricing regime on price variability with reference to the non-ferrous metals industry. Theoretical arguments are ambiguous, but in any case suggest that the extent of monopoly power is more important that the pricing regime as a determinant of variability. Slade (1991) argued that metals price volatility increased in the nineeen eighties relative to the seventies, and that this was associated with a move from administered producer pricing to exchange pricing. These claims are only partially supported. Extension of Slade's sample to the present indicates that any early differences between the variability of producer and exchange prices have now vanished.
\end{abstract}

JEL codes: GO, G1, L61

Key words : metals, futures, exchange pricing, producer pricing, price volatily

\section{Introduction}

Over recent decades, there have been two competing forms of market organization in the non-agricultural (metals and energy) primary sector - exchange

${ }^{*}$ Department of Economics, Queen Mary University of London, London E1 4NS, England (email: i.figuerola-ferretti@qmw.ac.uk).

${ }^{\dagger}$ FEWEC, Vrije Universiteit Amsterdam, De Boelelaan 1105, 1081 HV Amsterdam, The Netherlands (email: cgilbert@econ.vu.nl). 
pricing and producer (administered) pricing. Under the now dominant system of exchange pricing, products are sold "basis" an exchange price, or a short time average of such prices, at or near the delivery date. Under producer pricing, producers set product prices on a list basis, and transactions prices are negotiated at variable, often secret, discounts from the list prices. Economists tend to prefer exchange pricing on the arguments that it is informationally more efficient and that it inhibits price discrimination. By contrast, producing companies often suggest that producer pricing guarantees greater predictability.

In the post-1945 period, crude oil was subject to producer pricing, with prices set first by the oil majors and then by OPEC, until the breakdown of OPEC discipline together with the advent of oil futures trading resulted in a move to exchange pricing in the mid eighties. ${ }^{1}$ In non-ferrous metals, aluminium and nickel prices were also set by dominant producers through to the mid-eighties, but both are now exchange priced. ${ }^{2}$ Over the same period, copper saw producer pricing in the United States coexisting with exchange pricing elsewhere in the (non-socialist) world, although major producers attempted to "control" exchange prices for a period in the early sixties as a prelude to moving to producer pricing. ${ }^{3}$ Of major metals, only iron and steel are now priced by producers.

It is widely held in the metals industry that the move away from producer pricing has resulted in increased price variability, and this view was lent support by Slade's (1991) influential article - see also Radetzki (1990, p.55). Price variability is seen as imposing costs on producers, consumers and stockholders (Radetzki, 1990, pp.53-54). Advocates of exchange pricing often argue that, although exchange prices are more variable than producer prices, the liquidity of exchange markets allows agents to hedge against this increased variability, with the implication that increased price variability has little importance. However, once one takes account of possible risk premia,

\footnotetext{
${ }^{1}$ The New York Mercantile Exchange (NYMEX) started trading Gulf crude oil in 1983. The International Petroleum Exchange (IPE) followed with Brent crude in 1988.

${ }^{2}$ Aluminium and nickel trading started on the London Metal Exchange (LME) in 1979. The Comex division of NYMEX introduced an unsuccessful aluminium contract in the mid eighties, and relaunched aluminum trading in 1999.

${ }^{3}$ Copper has been traded on Comex and the LME through most of the twentieth century. It is now also traded in Shanghai and Singapore. See McNicol (1975) on the coexistence of producer and exchange pricing in copper and Prain (1975) on the attempt by the non-US copper mining companies to "control" price movements on the LME. Radetzki (1990) provides an overview of commodity pricing arrangements.
} 
commission and management costs, hedging will not be costless. This suggests that the welfare effects of exchange trading are ambiguous.

This question is also topical in that the preeminence of the London Metal Exchange (LME) in the pricing of non-ferrous metals is likely to come under threat in the coming years from internet-based trading systems. It is possible that competition for the physical and hedging business may result in lower market liquidity and greater volatility.

We are not aware of theoretical discussions of the relative variability of prices under producer and exchange pricing, although there has been substantial discussion of the question of whether futures trading reduces price variability - see Turnovsky (1983) for a summary. However, in this paper, we focus solely on the price discovery features of exchange trading that arise from centralization, and that literature is therefore not directly relevant. We suggest two effects from centralization which potentially affect price variability, but in opposite directions.

- Centralization pools shocks across different producer markets. The resulting risk sharing tends to reduce price variability.

- There is evidence that demand for metals is negatively related to price variability. Producers therefore have an incentive to smooth price movements. In a centralized market, by contrast, a sub-optimal degree of smoothing takes place.

Overall, therefore the volatility affects of a move from producer to exchange pricing is ambiguous. An alternative argument might be that "speculation" either increases or decreases price variability. However, this argument relates to the possible effects of centralization on storage, and/or the effects of futures trading on price discovery. In this paper we consider only the direct effects of centralization. ${ }^{4}$

Slade (1991) used monthly data on six metals over the sample 19701986 to examine, inter alia, whether prices are more variable under exchange pricing than producer pricing. She concluded (a) that price variability was higher in the second half of her sample relative to the first and (b) that this increase in variability was due in part to a shift to exchange pricing. We find support for the view that the variability of quoted producer prices was lower

\footnotetext{
${ }^{4}$ On storage, see Turnovsky (1983) and the references therein, and Gilbert (1989). On price discovery, see Stein (1986).
} 
than the variability of exchange prices over the period examined by Slade, but argue that the apparent increase in price variability she reports depends crucially on the Hunt silver manipulation. We show that if Slade's sample is extended to include more recent data, there appears little difference between the price variability associated with the two regimes. ${ }^{5}$ We argue that this is because, from the mid eighties, producer prices adjusted rapidly to changes in exchange prices.

\section{Theoretical Considerations}

If firms set prices on an administered basis, will this result in greater or lesser price variability than would arise if prices were set on an organized exchange? In order to answer this question, we need to know first, why producers might be concerned with price variability, and second, in the case that they are concerned by price variability, whether they can act to reduce it.

A difficulty in attempting to answer these questions is knowing how to characterize producer pricing. One approach is to suppose firms set prices that are held constant for long periods of time, with the implication that demand shocks are absorbed either by inventories or through production response. But this prompts the questions, for how long are prices maintained constant and why do firms choose to smooth prices.

One possible explanation of producer price smoothing behaviour would be in terms of a "menu cost" argument (Cechetti, 1986) - changing price lists is expensive. However, this argument has greater plausibility at the retail rather than the wholesale level - it is difficult to see that current contracting arrangements based on a negotiated premium or discount relative to the "unknown" exchange price, impose significant costs on firms. This suggests we should look for the explanation on the consumer rather than the producer side of the market.

We suggested above, price variability imposes costs on fabricators and/or semifabricators. If this is the case, price variability will be an argument to demand functions - offered a choice between alternative raw materials (eg copper versus plastic), relative price variability will be one factor influencing the choice. Note that in the metals industry, consumers of refined metals are typically metals semifabricating companies who work on narrow margins -

\footnotetext{
${ }^{5}$ In related work, Brunetti and Gilbert (1995) argued that the variability of LME metals prices is trendless from the mid seventies to the mid nineties.
} 
margin variability will increase the riskiness of their operations. This provides producers with an incentive to smooth prices - the less variable are prices, the higher they will be on average.

We investigated this hypothesis by introducing volatility into regressions of metals consumption on industrial production and price. (Detailed equation specifications and estimates are given in the appendix). We find a significant negative effect of price variability on the demand for tin, and smaller and near significant effect on the demand for copper and zinc. There was no evidence of this effect on the demand for aluminium, lead or nickel, but the aluminium and nickel samples are relatively short and lead consumption is dominated by car batteries where there is no substitute material. Overall, these results provide some support for the view that price variability imposes costs on metals consumers.

This argument establishes that producers have an incentive to smooth prices. However, whether or not they will be able to do this will depend on the competitive structure of the industry. In a perfectly competitive market, an individual producer would have no influence on the price he could obtain. Producer pricing requires either that firms compete in some dimension other than price (e.g. product quality); or that the market is segmented, so that different producers can charge different prices, with each producer exercising a degree of monopoly power in its own market. In practice, differences between different metals brands are slight, so that product homogeneity is a reasonable assumption in non-ferrous metals. ${ }^{6}$ We therefore prefer the market segmentation route.

Under exchange trading, a single price clears the entire market. Under this system, demand shocks, which would have affected only affect a single firm under a producer regime, are spread across the market. So long as shocks to different market segments are less than perfectly correlated, this diversification effect will reduce price variability relative to the producer pricing regime. This suggests that exchange pricing should give rise to lower price variability than producer pricing.

The desire on the part of producers to smooth prices works in the opposite direction. Firms will be conscious of the impact of price variability on the position of the demand function and therefore on their profits. If markets are segmented, each producer will aim for the profit-maximizing level of price variability by varying production or inventory in line with variations in con-

\footnotetext{
${ }^{6}$ See Lord (1991) for the contrary view.
} 
sumption. Exchange trading brings centralization, and in this case, although firms still have an incentive to smooth prices, any attempt by a single firm to unilaterally do this by varying its own production and/or inventory will have only a small effect on aggregate supply and hence the market price. Price smoothing may therefore be seen as generating externalities across the industry, while under producer pricing, these externalities were completely internalized. Firms therefore have less incentive to smooth than under producer pricing, and the extent of smoothing will decline as the number of firms in the industry rises. Alternatively, we may see price variability as a "public bad" which will persist in the competitive exchange pricing regime but which would be eliminated under a monopolistic regime.

Producers with monopoly power can therefore use their power to benefit consumers by stabilizing prices. But although producers who operate this type of regime maintain broadly constant list prices, they also typically offer variable but secret discounts on these list prices - it is therefore incorrect to see transactions prices as being completely smoothed. These variable discounts are a manifestation of monopolistic price discrimination. The overall conclusion is therefore that producers do have an incentive to smooth prices, but the possession of a degree of market power is the prerequisite for their being able to do this. But if they do possess monopoly power, it is likely that they will also attempt to discriminate. The implications are that the exercise of monopoly power is jointly responsible for price discrimination and for price smoothing; and that if a move to exchange trading appears to give rise to greater price variability, this will primarily reflect a reduction in monopoly power.

\section{Slade's Analysis}

Slade (1991) argued that metals price volatility increased in the nineteen eighties relative to the seventies, and that exchange pricing results in greater price variability than producer pricing. The prices she analyzed are those of silver $(\mathrm{Ag})$, aluminium $(\mathrm{Al})$, copper $(\mathrm{Cu})$, nickel $(\mathrm{Ni})$, lead $(\mathrm{Pb})$ and zinc (Zn). She compared price variability in two sub-samples, 1970-79 and 198086. Table 1 summarizes the trading regimes for these metals. 


\begin{tabular}{|c|c|c|}
\hline \multicolumn{3}{|c|}{ Table 1: Metals Trading Structures } \\
\hline & Active Exchanges & Producer Pricing \\
\hline $\mathrm{Ag}$ & Comex $^{7}$ & None \\
\hline Al & LME (from 1979) ${ }^{8}$ & List prices until late ' $80 \mathrm{~s}$ \\
\hline $\mathrm{Cu}$ & LME, Comex & List prices in USA until late '80s \\
\hline $\mathbf{N i}$ & LME (from 1979) & List prices until late ' $80 \mathrm{~s}$ \\
\hline $\mathrm{Pb}$ & LME & List prices in USA until late '80s \\
\hline $\mathbf{Z n}$ & LME & List prices until late ' $80 \mathrm{~s}$ \\
\hline
\end{tabular}

In what follows, we suggest that Slade's conclusions are unduly influenced by the inclusion of silver in her sample. Silver differs from the other five metals Slade considers in that it is in part a precious as well as an industrial metal, ${ }^{9}$ and that it has no recent history of producer pricing. Most seriously, the silver market was manipulated over 1979-80 (the so-called Hunt episode), with the consequence that silver prices increased from under $\$ 6$ per ounce to over $\$ 38$ per ounce in less than one year. We contend that this episode is largely responsible for Slade's conclusions that price volatility increased in the eighties, and that exchange pricing generates greater volatility than exchange pricing. Silver provides the only instance in Slade's sample in which a regulatory authority has established manipulation of metals futures,${ }^{10}$ and it therefore seems reasonable to regard it as exceptional.

We have monthly averages of price quotations for Slade's six metals for the twenty-eight year period 1970-1997. We divide the sample into four subperiods: Period I (1970-79) and Period II (1980-1986) are those analyzed by Slade with the break corresponding to the introduction of futures trading in aluminum and nickel. We define Period III as covering 1987 to 1993, and

\footnotetext{
${ }^{7}$ Silver was also traded for parts of this period on the Chicago Board of Trade and the LME.

${ }^{8}$ Comex also traded aluminum over the period 1983-86. A new contract was introduced in 1999 .

${ }^{9}$ Silver is hold as a store of value in certain countries, most notably India and Pakistan, and these stocks have implications for price variability.

${ }^{10}$ The CFTC case against the Hunt brothers is discussed in Williams (1995). In May 1998, the CFTC issued an opinion and order against Sumitomo Corporation of Japan in which they found that Sumitomo had upwardly manipulated the price of copper and copper futures (CFTC Docket No. 98-14). In May 1999, the CFTC filed proceedings against General Minerals and Metals (GMM) and others claiming manipulation of the copper market (CFTC Docket No. 99-11). These claims relate to the period 1993-96.
} 
Period IV as 1994-97. Period III covers the metals price boom of 1987-90 while Period IV saw quieter market conditions. Extension of the sample to more recent data is useful because it permits examination of price variability in a period in which exchange pricing has become dominant. But because producer prices typically differed little from exchange prices over the nineties, the interesting comparison is of Periods III and IV with periods I and II, rather than the comparison of exchange and producer prices in Periods III and IV.

In Periods I and II we use Slade's data. ${ }^{11}$ We update these data to Periods III and IV, using Datastream for exchange price quotations and Metal Statistics (various issues) for producer prices. Data definitions are as in Slade. Again following Slade, we measure price variability as the variance of the monthly logarithmic change in prices in each sub-period, although in what follows, we quote these variability measures as standard deviations. In principle, this would give a 6 (metals) times 4 (sub-samples) times 2 (pricing regimes) block of variabilities, a total of 48 observations. However, there is a number of gaps: there are no producer prices for silver (4 gaps) and there are no exchange prices for aluminum and nickel in Period I ( 2 gaps). Furthermore, although there are two separate zinc producer price quotations for Periods 1 and II (one European and one north American) we have been unable to obtain European quotations for Periods III and IV. We therefore have a total of 42 variability observations.

In Tables 2 and 3, which correspond to Table IV in Slade, we report the variability of metals prices by time period (averaging variances across metals and price regimes, Table 2) and by pricing regime (averaging variances across metals and time periods).

\begin{tabular}{|l|c|c|c|c|c|}
\hline \multicolumn{5}{|c|}{ Table 2: Price Variability by Time Period } \\
\hline & I & II & III & IV & I - IV \\
\hline Including silver & $5.58 \%$ & $6.07 \%$ & $8.21 \%$ & $5.44 \%$ & $6.30 \%$ \\
\hline Excluding silver & $5.19 \%$ & $4.81 \%$ & $8.43 \%$ & $5.52 \%$ & $5.96 \%$ \\
\hline
\end{tabular}

The increase in price variability reported by Slade between periods I and II is apparent in the first row of Table $2 .{ }^{12}$ However, this increased variabil-

\footnotetext{
${ }^{11}$ We are grateful to Margaret Slade for allowing us to use her data. Slade adjusted her aluminium prices to a transaction basis but we have been unable to reproduce these changes. As a consequence, our results differ slightly from those she reports. However, these differences do not have any substantive implications.

${ }^{12}$ Slade omitted the producer prices for copper and nickel for her calculations for Period
} 
ity disappears when silver is dropped from the sample - price variability in Period II is actually lower than in Period I. Furthermore, the non-parametric Wilcoxen test for equality of means, used by Slade, fails to reject the null of equality even when silver is present (test statistic is 142 which is less than the $5 \%$ critical value of 167). There is therefore no basis in fact for Slade's claim that volatility increased between these two periods. Price variability does however increase in Period III, when metals were in tight supply, but falls back in Period IV. This is in line with the results reported in Brunetti and Gilbert (1995), who also developed a fundamentals-based model of metals price variability.

\begin{tabular}{|l|c|c|c|}
\hline \multicolumn{4}{|c|}{ Table 3: Price Variability by Pricing Regime } \\
\hline & Periods 1 \& II & Periods III \& IV & All Periods \\
\hline Exchange (incl. Ag) & $7.15 \%$ & $7.06 \%$ & $7.33 \%$ \\
\hline Exchange (excl. Ag) & $6.11 \%$ & $7.35 \%$ & $6.89 \%$ \\
\hline Producer & $3.86 \%$ & $7.67 \%$ & $5.06 \%$ \\
\hline Wilcoxen test (incl. Ag) & $\mathbf{5 5 ( 5 1 )}$ & $34(42)$ & $\mathbf{5 3}(51)$ \\
\hline Wilcoxen test (excl. Ag) & $43(47)$ & $26(33)$ & $41(47)$ \\
\hline
\end{tabular}

We now consider price variability by pricing regime. Column 1 of Table 3 shows the higher price variability associated with exchange pricing in Slade's sample, but also demonstrates that this increased price variability is moderated when silver is excluded from the sample. ${ }^{13}$ The final two rows of the table report the Wilcoxen equality of means test for the variability of exchange and producer pricing, first including and the excluding silver. The upper two-sided critical value for the test corresponding to $5 \%$ size is given parenthetically. In agreement with Slade, we can reject the hypothesis of equality when silver is included, but not if silver is excluded. In column 2 of Table 3, we see that the price variability is actually lower for exchange prices in the final two periods, although this difference is not significant. Even if exchange pricing did result in greater price variability historically, this is no longer the case. Pooling the two sub-samples gives comparable results

II. The figures we give in Table 2 include these prices. Using the same basis as Slade, our Period II variability statistics are $6.47 \%$ with silver included and $5.06 \%$ with silver excluded. Our results are therefore not dependent on treatment of copper and nickel in Period II. The variability figures for Periods III and IV reported in Table 2 are based on all available price quotations.

${ }^{13}$ This result is again unaffected by the treatment of copper and nickel in Period II. (The variability statistic for the producer prices in Periods I and II becomes $3.87 \%$ ). 
to those obtained from the first sub-sample. These tests therefore provide weak evidence in favour of the claim that exchange pricing is associated with greater price variability than producer list pricing.

As Slade notes, potentially more powerful tests can be obtained from paired comparison of producer and exchange prices in periods in which both operate. A further advantage of this comparison is that it will not be sensitive to the anomalous behaviour of the silver market, since the absence of a silver producer price eliminates it from this comparison. The results of the paired comparisons, which use the Wilcoxen signed rank test, are given in Table 4 (95\% upper tail critical values in parentheses). ${ }^{14}$

\begin{tabular}{|l|c|c|c|}
\hline \multicolumn{4}{|c|}{ Table 4: Paired Variability Tests } \\
\hline & Periods I \& II & Periods III \& IV & Periods I-IV \\
\hline All metals & $\mathbf{3 2}(28)$ & $6(19)$ & $\mathbf{8 0}(76)$ \\
\hline Slade's sample & $\mathbf{1 9}(19)$ & - & - \\
\hline
\end{tabular}

These comparisons confirm Slade's finding of a significant difference between the variability of exchange and producer prices in Periods I and II, either using the entire sample (row 1), or omitting copper and nickel producer prices in Period II (row 2). However, the differences cease to be significant in Periods III and IV, confirming our earlier observation that producer prices moved closely with exchange prices over these later periods.

\section{The Convergence of Exchange and Producer Prices}

The apparent convergence of exchange and producer price variability over the more recent periods prompts us to ask investigate the directions of causality between exchange and producer prices for those metals where the two systems coexist. If exchange markets are characterized by thin trading and are illiquid, producers have considerable latitude in setting prices and can, if they so choose, maintain prices at constant levels for extended periods of time. In such circumstances, exchange prices tend to be speculations on possible changes in producer list prices - see Ghosh et al (1987). This may have been broadly the case in the sample Slade investigated. However, once exchanges become liquid, metals consumers can purchase from (or resell to) exchanges if this becomes attractive, and this possibility forces producers to adjust their

\footnotetext{
${ }^{14}$ These comparisons use the US producer price for zinc.
} 
prices more frequently, in line with exchange quotations (MacAvoy, 1988, p.13). This suggests that while in the first half of our sample we might expect to find producer price changes causing exchange price changes, but not vice versa, in the second half of the sample, we might expect this to be reversed.

We investigate this hypothesis by performing Granger non-causality tests on the time series of monthly price returns. We divide the overall sample into two sub-samples, 1970-83 and 1984-97, each containing 167 monthly observations. ${ }^{15}$ The results of the non-causality tests are reported in Table 5 where $P \rightarrow E$ indicates a test of the null hypothesis that producer prices Granger non-cause exchange prices (so a significant value, implying rejection of the null, indicates causality), while $E \rightarrow P$ indicates a test of the null hypothesis that exchange prices Granger non-cause producer prices. ${ }^{16}$

\begin{tabular}{|l|c|c|c|c|}
\hline \multicolumn{5}{|c|}{ Table 5: Granger Non-Causality Tests } \\
\hline & \multicolumn{2}{|c|}{$1970-83$} & \multicolumn{2}{c|}{$1984-97$} \\
\hline & $P \rightarrow E$ & $E \rightarrow P$ & $P \rightarrow E$ & $E \rightarrow P$ \\
\hline $\mathrm{Al}$ & $\mathrm{F}_{1,55}=1.80$ & $\mathrm{~F}_{1,55}=0.26$ & - & - \\
\hline $\mathrm{Cu}$ & $\mathrm{F}_{1,163}=\mathbf{1 1 . 1 0}$ & $\mathrm{F}_{1,163}=\mathbf{1 0 . 7 8}$ & $\mathrm{F}_{1,165}=0.11$ & $\mathrm{~F}_{1,165}=\mathbf{3 3 . 8 7}$ \\
\hline $\mathrm{Ni}$ & $\mathrm{F}_{1,48}=0.13$ & $\mathrm{~F}_{1,48}=1.76$ & $\mathrm{~F}_{1,165}=\mathbf{4 . 7 7}$ & $\mathrm{F}_{1,165}=\mathbf{3 0 . 1 0}$ \\
\hline $\mathrm{Pb}$ & $\mathrm{F}_{1,163}=1.03$ & $\mathrm{~F}_{1,163}=\mathbf{1 3 . 8 0}$ & $\mathrm{F}_{1,165}=0.83$ & $\mathrm{~F}_{1,165}=\mathbf{1 8 . 5 0}$ \\
\hline $\mathrm{Zn}(\mathrm{NA})$ & $\mathrm{F}_{1,163}=\mathbf{4 . 5 5}$ & $\mathrm{F}_{1,163}=\mathbf{1 8 . 5 8}$ & $\mathrm{F}_{1,153}=1.43$ & $\mathrm{~F}_{1,153}=1.33$ \\
\hline $\mathrm{Zn}(\mathrm{Eu})$ & $\mathrm{F}_{1,163}=0.17$ & $\mathrm{~F}_{1,163}=\mathbf{1 8 . 9 7}$ & - & - \\
\hline
\end{tabular}

The results of these tests show causality from exchange to producer prices over both periods, but most emphatically in the later period. However, only in nickel is there evidence of causality from producer to exchange prices in the period after 1984. This is consistent with the view expressed above that, where producers still retain list prices, they are now obliged to move these in line with exchange price movements.

Discussing the relationship between producer and exchange prices, Ghosh et al (1987, p.67) considered two polar cases, in which one or other price was dominant, and an intermediate case, in which the two interacted. Slade's Period I relates to a time in which aluminium and nickel conformed to the first polar case. Even after the start of futures trading in these two metals,

\footnotetext{
${ }^{15}$ There are insufficient observations on aluminium and nickel for this technique to be implemented in the first half of the sample.

${ }^{16}$ The tests use a common lag length of one, chosen on the basis of the Schwartz Criterion. They are qualitatively robust to an increase in lag length.
} 
the aluminium and nickel producer prices in the early nineteen eighties were little more than speculations on future movements of the respective producer prices. But by the latter part of the nineteen nineties, the major non-ferrous metals markets had made the complete transition to exchange-priced markets where producer prices, to the extent that they still existed, deviated little from exchange prices.

The relative variability of exchange and producer prices will change depending on their relative importance - when the exchange price is the residual (Slade's Period I) it will tend to be more variable that the producer price, while when the producer price simply adjusts to the exchange price they will have very similar variabilities. This suggests that one should be cautious in extrapolating results from one period to another if there have been major changes in market characteristics between the two periods. In this particular instance, the claim that exchange-based pricing in non-ferrous metals has resulted in greater variability than producer pricing appears to be true only of a particular phase in the evolution of market structure.

\section{Conclusions}

It is likely that price variability imposes costs on metals consumers and it is widely supposed that the move from producer pricing to exchange-based pricing has resulted in an increase in metals price variability. Economic theory does not support this link but suggests that both the ending of producer pricing and any increase in price variability may both be due to a reduction in producers' monopoly power.

Slade (1991) argued that, empirically, the move away from producer pricing increased metals price variability. We have re-examined and updated her results. This claim has two components: exchange pricing gives rise to more variables prices than producer pricing, and that price variability increased over the period in which exchange pricing became dominant. The second claim (that price variability increased between the nineteen seventies and eighties) is not robust to the exclusion of silver from her sample. This suggests that this conclusion may rely on the Hunt manipulation. In extending Slade's data to the present, we confirm earlier research which suggests that there is no general tendency for price variability to increase. This first claim is supported in the sample Slade examined, although exclusion of silver weakens the evidence. However, extension of her sample shows that there is 
no longer any divergence between price variability between the two sets of institutions. Granger non-causality tests support the view that this is because producers are now obliged to adjust list prices in line with exchange prices.

The objective of this research has been to clarify the claim that the move to exchange-based pricing has increased the variability of non-ferrous metals prices. This claim is partially true - producer list prices were less variable than exchange prices during the nineteen seventies and eighties - but also partially false - there has been no general tendency for metal price volatility to increase, despite the move to exchange pricing. The research also suggests two important issues which we hope to answer in future research.

- We have noted that producer pricing regimes were frequently characterized by widespread and probably discriminatory discounting. How variable were actual transaction prices, as distinct from list prices, under producer pricing? In particular, were transactions prices more variable than exchange prices?

- The theoretical analysis suggests that price variability depends more on the extent of producers' monopoly power than on the actual pricing regime. Indeed, administered pricing presupposes that producers do possess a significant degree of monopoly power. This suggests that decreased concentration, in particular in the aluminium and nickel industries, may have resulted in producer pricing becoming unviable. This hypothesis deserves quantitative evaluation.

\section{A Appendix: Estimated Demand Functions}

Here we report estimated metals demand functions for copper, tin and zinc using annual data over the sample 1974 to 1998 (25 observations). Refined consumption (cons) is regressed on the deflated real price of the metal (price, treated as endogenous), the change in industrial production (IP, as a measure of the position of the demand curve), a time trend (trend), and intra-year daily price volatility $(\mathrm{vol})$. The level of LME warehouse stocks (stocks) is used as an instrument. ${ }^{17}$ Equation specifications are similar across metals, with minor differences in lag specifications. Estimation is by two stage least

\footnotetext{
${ }^{17}$ Refined consumption is on a "non-socialist" world basis - ie it excludes China, the ex-Soviet Union and its successor countries, the ex-communist east European countries, and Cuba, for which data were unreliable prior to the nineteen nineties, and where (in
} 
squares for copper and tin, and by Ordinary Least Squares for zinc (where the price variable was dropped as incorrectly signed). The estimated demand function (standard errors in parentheses) are:

\section{Copper}

$$
\begin{aligned}
& \ln \left(\text { cons }_{t}\right)=\begin{array}{c}
2.463 \\
(1.751)
\end{array}+\begin{array}{c}
0.0077 \\
(0.0041)
\end{array} \text { trend }_{t}+\underset{(0.164)}{0.709} \ln \left(\text { cons }_{t-1}\right) \\
& +\underset{(0.599)}{2.493} \Delta \ln \left(I P_{t}\right)-\underset{(0.121)}{0.277} \Delta \ln \left(\text { price }_{t}\right) \\
& -\begin{array}{c}
0.257 \\
(0.216)
\end{array}\left(\frac{\text { vol }_{t-1}+v l_{t-2}}{2}\right) \\
& \text { s.e. }=0.0480, D W=1.14 \text {, Instrument Validity } \chi^{2}(3)=2.02 \\
& \text { Instruments }=\ln \left(\text { price }_{t-1}\right) \ln \left(I P_{t-1}\right)\left(\frac{\text { stocks }}{\text { cons }}\right)_{t-1}\left(\frac{\text { stocks }}{\text { cons }}\right)_{t-2}
\end{aligned}
$$

$\operatorname{Tin}^{18}$

$$
\begin{aligned}
& \ln \left(\text { cons }_{t}\right)=\underset{(0.424)}{1.338}-\underset{(0.0022)}{0.0056} \text { trend }_{t}+\underset{(0.065)}{0.839} \ln \left(\text { cons }_{t-1}\right) \\
& +{ }_{(0.149)}^{1.001} \Delta \ln \left(I P_{t}\right)-\underset{(0.029)}{0.085} \ln \left(\text { price }_{t}\right) \\
& -{ }_{(0.170)}^{0.533} \text { vol }_{t}+{ }_{(0.0139)}^{0.0039} \text { Dummyt }_{\text {Dum }} \\
& \text { s.e. }=0.0213, D W=2.50 \text {, Instrument validity } \chi^{2}(4)=4.07 \\
& \text { Instruments }=\ln \left(\text { price }_{t-1}\right) \ln \left(I P_{t-1}\right)\left(\frac{\text { stocks }}{\text { cons }}\right)_{t-1}\left(\frac{\text { stocks }}{\text { cons }}\right)_{t-2} v_{t-1}
\end{aligned}
$$

certain cases) they remain unreliable. Data sources: Refined consumption - World Bureau of Metal Statistics, World Metal Statistics (various issues); Industrial production and US Manufactures Price Index (used as price deflator) - International Monetary Fund, International Financial Statistics (June 1999); Metals prices - Brunetti and Gilbert (1995), updated from LME web site (http://www.lme.co.uk/Stats.htm), with the exception of the tin price over the period 1985-89, taken as the Kuala Lumpar price (source World Metal Statistics); LME warehouse stocks (used in constructing instruments) - LME website. Data are available from the authors on request.

${ }^{18}$ Tin trading was suspended on the LME from 24 October 1985 until 1 August 1989. The tin price volatility is calculated from LME daily price data for the incomplete years 1985 and 1989, and is set to $5 \%$ for 1986-88. A dummy variable (Dummy), equal to one in 1986-89, is included in the regression to account for the arbitrainess of this measure. 


\section{Zinc}

$$
\begin{aligned}
& \ln \left(\text { cons }_{t}\right)={ }_{(0.857)}^{4.149}+\underset{(0.0020)}{0.0099} \text { trend }_{t}+{ }_{(0.104)}^{0.492} \ln \left(\text { cons }_{t-1}\right) \\
& +{ }_{(0.229)}^{1.172} \Delta \ln \left(I P_{t}\right)-{ }_{(0.076)}^{0.109} \text { vol }_{t-2} \\
& R^{2}=0.966, \text { s.e. }=0.0307, D W=2.15
\end{aligned}
$$

Similar equations (not reported) were estimated for lead and, on shorter samples (starting in 1984) for aluminium and nickel. Both the price elasticity and volatility semi-elasticities are best defined in the tin demand equation. The most important use of tin is in tin plate, which competes with aluminium in the can market. In the other metals considered, the substitution interface is less evident.

\section{References}

Brunetti, C. and Gilbert, C.L. (1995), "Metals price volatility, 1972-95", Resources Policy, 21, 237- 254.

Cechetti, S. (1986), "The frequency of price adjustment: a study of the newsstand prices of magazines", Journal of Econometrics, 31, 255-74.

Ghosh, S., Gilbert, C.L. and Hughes Hallett, A.J. (1987), Stabilizing Speculative Commodity Markets, Oxford, Oxford University Press.

Gilbert, C.L. (1989), "Futures trading, storage and price stabilization", Review of Futures Markets, 8, 152-78.

Lord, M. (1991), Imperfect Competition and International Commodity Trade, Oxford, Clarendon Press.

MacAvoy, P.W. (1988), Explaining Metals Prices, Boston, Kluwer.

McNicol, D.L. (1975), "The two price systems in the copper industry", Bell Journal of Economics, 6, 50-73.

Prain, R. (1975), Copper: The Anatomy of an Industry, London, Mining Journal Books.

Radetzki, M, (1990) A Guide to Primary Commodities in the World Economy, Oxford, Blackwell.

Slade, M. E. (1991), "Market structure, marketing method, and price instability", Quarterly Journal of Economics, 106, 1309-1339.

Stein, J.L. (1986), The Economics of Futures Markets, Oxford, Blackwell. 
Turnovsky, S.J. (1983), "The determination of spot and futures prices with storable commodities", Econometrica, 51, 1363-88.

Williams, J. (1995), Manipulation on Trial, Cambridge, Cambridge University Press. 


\section{Q Queen Mary \\ University of London}

This working paper has been produced by the Department of Economics at Queen Mary, University of London

Copyright @ 2001 Isabel Figuerola-Ferretti and Christopher L. Gilbert. All rights reserved.

Department of Economics

Queen Mary, University of London

Mile End Road

London E1 4NS

Tel: +44 (0)20 78825096 or Fax: +44 (0)20 89833580

Email: j.conner@qmw.ac.uk

Website: www.econ.qmw.ac.uk/papers/wp.htm 